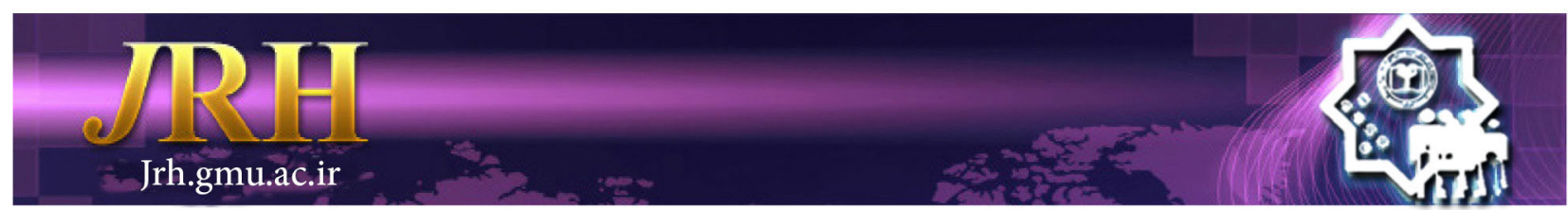

\title{
The relationship between phone dependency with psychological disorders and academic burnout in students
}

Reza Noruzi Kuhdasht ${ }^{1}$, Zahra Ghayeninejad ${ }^{2}$, Naser Nastiezaie ${ }^{3}$

\author{
Journal of Research \& Health \\ Social Development \& Health Promotion \\ Research Center \\ Vol. 8, No. 2, Mar \& Apr 2018 \\ Pages: 189- 195 \\ DOI: $10.29252 /$ jrh.8.2.189 \\ Original Article
}

1. Correspondence to: Department of Educational Administration, Faculty Education and Psychology, Shiraz University, Shiraz, Iran Email: r.norouzi20@yahoo.com

2. Department of Educational Research, University of Sistan and Baluchestan, Faculty Education and Psychology, Zahedan, Iran

3. Department of Educational Administration and Planing, University of Sistan and Baluchestan, Faculty Education and Psychology, Zahedan, Iran

\section{Received: 14 May 2017}

Accepted: 10 Dec 2017

How to cite this article: Noruzi Kuhdasht R, Ghayeninejad Z, Nastiezaie N. The relationship between mobile phone dependency with psychological disorders and academic burnout in students. $J$ Research \& Health2018; 8(2): 189- 195

\begin{abstract}
Despite the widespread use of mobail phones in Iranian students, psychological and behavioral effects of addiction to it and its consequences have not been investigated yet. The aim of this study was to determine the relationship between cell phone dependency with psychological disorders and academic burnout among nursing and midwifery students. In this study, 169 students were chosen through stratified random sampling method. Data collection tools included mobile phone addiction index, symptom check list-90- Revision and academic burnout inventory. Correlation coefficients of mobile phone dependency with psychological disorders was 0.487 and according results from regression analysis mobile phone dependency predicted $23.8 \%$ of the variance of psychological disorders. Correlation coefficients of mobile phone dependency with academic burnout was 0.677 and results from regression analysis mobile phone dependency explained 47.6 of the variance academic burnout. Considering the positive and significant relationship between cell phone usage with psychological disorders and students' academic burnout, identifying the people at risk and holding mobile phone injury training workshops is recommended.
\end{abstract}

Keywords: Burnout, Dependency, Disorders, Mobile Phone, Psychological Students

\section{Introduction}

Until this time, no technology could be accelerated so quickly as mobile phone. Over a ten-year period, mobile phone traffic has tripled among people compared to other telecommunications systems such as landlines and the Internet [1]. A wide range of new functions of mobile phones such as cameras, computers, music playback and the Global Positioning System (GPS) has led to tendency to it [2]. In a study, the application priorities among Iranian young people was various mobile phone features respectively as Short Message Service (SMS), in-town talking, music storage, alarm clock, photo taking, use of bluetooth, playing, filming, storing and watching movies and clips [3]. But excessive use has the risk of addiction [4]. According to statistics of telecommunication institutions, more than 5 million unique users in the world namely about two thirds of the world's population were using mobile mobile services. It should be noted that the Telecommunication 
Institute predicts that by 2020 the number of mobile subscribers in India will grow to 310 million and the number of mobile users will increase from 5 billion to 5.7 billion people worldwide [5] In Switzerland, almost 90\% of the people have mobile [6]. Statistics in Iran indicate that the penetration rate of Subscriber Identification Module (SIM) cards over the past 10 years has been raised from 46.8 percent in 2007 to 193.76 percent at the end of 2016 . Currently, 33 million and 246 thousand and 69 subscribers use mobile mobiles internet [7]. This addiction leads to the emergence of problems related to mental health [8]. Addiction to mobile phone is a kind of impulsive behavior in using mobile phone that, the use by a person not only has a sense of relief; but requires more use and turning to more advanced phones and in the case of deprivation causes isolation [9]. Detection of mobile phone addiction is not easy such as alcoholism [10]. The signs of this addiction are regular and frequent checks of received messages, a sense of unrest in the case of no response to phone or message sent, constant need to buy the latest model phones with newer facilities each month and the need to communicate, being informed of events and being available to others [11]. Addicted people have the feelings of depression, loss and loneliness without mobile phone [12]. The empirical findings support a negative impact of excessive use of mobile phone on the physical and psychological health of the users [13]. If addicts do not have the mobile phone so they would have the feeling of depression, defeat and loneliness. Sometimes their job and life are disturbed due to repeated calls, text messages, surf the Web and online chats [14].

Mobile dependence has three symptoms of disruption of life, endure deprivation, and force-insist to use mobile phone. A) Disruption of life: sometimes work and live of mobile phone addicts are disrupted through repeated calls, text messages, surfing the web and online chats [10]. These people often sacrifice their sleep for communication and forget about eating and exercising. There are some reports of deaths during the use of the Internet caused by a heart attack, which can be due to physical disorders such as sleep, sedentary and suicidal behavior due to Internet addiction and due to stress. Unfortunately, mobile phone and Internet addiction can lead to ignoring the family relationships, breakdown of social relationships, educational downturns, job problems and high expenditures for using it, which can be economically problematic [15]. Endurance deprivation; the Internet addiction disorder is included in the subset of impulse control disorders. These people do not have resistance to impulses, emotions or temptations that are harmful to them or to others, but they may consciously resist the impetus [16]. The deprivation is the negative physiological and psychological response to the lack of use of mobile phones in the person's behavior, which if the person is not able to withstand this deprivation and it results in loss of control and excessive and repetition use of the mobile phone [14]. Another consequence of deprivation is depression and disappointment so that, whenever something causes the person to be deprived of the mobile phone or limits his access to the internet, he or she feels depressed or anxious and frustrated [17]. C) Forceinsist: It means feeling the need for more use of the internet and mobile in order to achieve satisfaction. unsuccessful efforts to control, cut back or stop internet use, restlessness, irritability, depression when using the internet is interrupted, explaining and trying to show the time of using the internet is low are some of the symptoms of persist and force in excessive use of the internet and mobile phones. If addicted people do not use mobile phones, the feel depressed, defeat and lonely [10].

Mental health not merely includes the absence of mental disorders but also includes features of improvement and development of the mental health status [18]. Students with psychological disorders experience problems related to education, such as concentrating problems, distractibility, and inappropriate behavior, lack of social skills, helplessness, impulsivity behavior and anxiety [19]. Due to stressing factors such as clinical setting, having compact 
courses in training courses medical students are at risk for mental and emotional disorders more than other students and thus have less general health compared to non-medical students [20].

Academic burnout can be defined as a combination of fatigue from assignments, pessimism toward school and feelings of inadequacy in education [21]. Due to assignments such as quizzes, articles; presentations students are somehow practitioners and are prone to burnout [22]. Students who have academic burnout usually experience symptoms such as: enthusiastic about the curriculum, reluctance to attend regular classes, non-participation in classroom activities, absence and feelings of meaninglessness and incompetence in learning curriculum [23]. The aim of this study was to determine the relationship between dependence on mobile phones with psychological disorders and academic burnout in nursing and midwifery students of Zahedan.

\section{Method}

This study is correlation. The population includes undergraduate students at school of nursing and midwifery, Zahedan university of medical sciences in 2016-2017 that 169 students (71 boys and 98 girls) were selected as the samples with stratified (in terms of gender and field of study) - random sampling method and on the basis of Cochran sampling formula.

Three questionnaires were used to collect information:

Mobile phone addiction index: A self-report instrument was developed by Koo in 2009 [24]. Inventory measures the dependence on the mobile phone in the form of 20 items and 3 factors deprivation enduring (items 1 to 7),life dysfunction (items 8 to 13) and force-insist (items 14 to 20). Each of the items has four options of very high, high, low and very low scored from $1=$ very low to $4=$ very high. The reliability was reported Cronbach's coefficient of 0.92 [24].

Symptom check list-90-revision: This consists of 9 items: Somatization, obsession, interpersonal sensitivity, depression, anxiety, hostility, and phobia, paranoid and psychotic thoughts. Answers provided to each of the test materials are classified on a 5-degree scale "no", "rarely", "somewhat", "high", and "strongly" with a minimum score of zero for "no" and maximum score of four for " high". Higher test score in 9-item subscales and in total is a sign of psychological disorders. This test has been used frequently to assess the extent of psychopathology in Iranian different populations. In surveys conducted in Iran to assess the reliability and validity of SCL_90_R this questionnaire is based on reliability and validity acceptable [25-26]. The validity of the questionnaire was as follows: Somatization 0.49 , obsession 0.36 , interpersonal sensitivity 0.43 , depression 0.44 , anxiety 0.47 , hostility 0.42 , phobia 0.34 , paranoid 0.37 and psychotic thoughts 0.39 [27]. The reliability of the questionnaire is as follows through Cronbach's alpha: Somatization 0.9, obsession 0.89, interpersonal sensitivity 0.87 , depression 0.92 , anxiety 0.88 , hostility 0.79 , phobia 0.79 , paranoid 0.75 and psychotic thoughts 0.82 [27]. The reliability with test-retest was reported 0.94 [25].

Academic burnout inventory: This inventory is developed by Bresó et al. and studies academic burnout with 15 items and three components of academic fatigue (5 items), educational apathy (4 items) and academic failure (6 items). Participants will be asked to identify their answer on a 7-point Likert spectrum from never $=0$ to always $=6$ [28]. In the study conducted by Hosseinpur et al. the Cronbach's alpha calculated for the whole questionnaire is 0.85 and for components of academic fatigue, educational apathy and academic failure, of $0.72,0.82$ and 0.71 are respectively obtained [29].

In this study the content validity was used to determine the validity of the questionnaire so the questionnaires were confirmed by university professors. Cronbach's alpha coefficient was used to determine the reliability that the coefficients obtained for questionnaires of cell mobile dependence; psychological disorders and academic burnout were $0.78,0.81$ and 0.73 respectively. Methods were such that after determining the 
sample size, the data were collected by direct referring to the school by interviewers so that interviewers visit the school environment and distributed questionnaires among the students randomly and questionnaires were collected after completion. The students were included with informed consent. The questionnaire was completely anonymously and participants were assured that their information is confidential and any time they can be excluded. Questionnaires are completed between 15 to 20 minutes. Data were analyzed by using Pearson correlation coefficient and multiple regression analysis with SPSS-21.

\section{Results}

In this study, 169 undergraduate students from the Faculty of Nursing and Midwifery of Zahedan University of Medical Sciences were studied through questionnaires that 71 males (42.01\%) and 98 female (57.99\%), 34 married (20.11\%) and 135 single (790.89\%), 68 nursing students $(40.23 \%), 56$ midwifery students $(33.13 \%)$ and 45 operating room students $(26.62 \%)$ were included.

To determine the relationship of dependency on mobile phone with psychological disorders the Pearson correlation coefficient was used in the first step the findings are reported in Table 1.

Table 1 Correlation coefficients of dependence on mobile phones with psychological disorders

\begin{tabular}{|c|c|c|c|c|c|c|c|c|c|c|}
\hline \multirow[t]{2}{*}{ Variable } & \multirow[b]{2}{*}{ M } & \multirow[b]{2}{*}{ Sid } & \multicolumn{2}{|c|}{$\begin{array}{c}\text { Endure } \\
\text { deprivation }\end{array}$} & \multicolumn{2}{|c|}{ Disruption of life } & \multicolumn{2}{|c|}{ Force-insist } & \multicolumn{2}{|c|}{$\begin{array}{l}\text { The overall } \\
\text { dependency on } \\
\text { mobile phone }\end{array}$} \\
\hline & & & $\mathrm{r}$ & $\mathrm{P}$ & $\mathrm{r}$ & $\mathrm{P}$ & $\mathrm{r}$ & $\mathrm{P}$ & $\mathrm{r}$ & $\mathrm{P}$ \\
\hline Aggression & 11.02 & 4.68 & 0.283 & 0.000 & 0.152 & 0.049 & 0.205 & 0.007 & 0.269 & 0.000 \\
\hline Anxiety & 16.99 & 6.04 & 0.376 & 0.000 & 0.324 & 0.000 & 0.366 & 0.000 & 0.446 & 0.000 \\
\hline Obsession & 19.06 & 5.32 & 0.321 & 0.000 & 0.276 & 0.000 & 0.303 & 0.000 & 0.376 & 0.000 \\
\hline Interpersonal sensitivity & 18.30 & 5.62 & 0.222 & 0.004 & 0.240 & 0.002 & 0.273 & 0.000 & 0.309 & 0.000 \\
\hline $\begin{array}{l}\text { Deepening } \\
\text { hypochondria }\end{array}$ & 19.43 & 6.03 & 0.17 & 0.027 & 0.173 & 0.025 & 0.171 & 0.026 & 0.213 & 0.005 \\
\hline Psychosis & 16.92 & 6.34 & 0.237 & 0.002 & 0.277 & 0.000 & 0.280 & 0.000 & 0.330 & 0.000 \\
\hline Paranoia & 15.65 & 5.18 & 0.185 & 0.016 & 0.199 & 0.010 & 0.146 & 0.058 & 0.215 & 0.005 \\
\hline Depression & 19.74 & 7.82 & 0.237 & 0.002 & 0.217 & 0.005 & 0.427 & 0.000 & 0.386 & 0.000 \\
\hline Fear & 12.34 & 5.71 & 0.309 & 0.000 & 0.244 & 0.001 & 0.341 & 0.000 & 0.384 & 0.000 \\
\hline $\begin{array}{l}\text { Psychological disorders } \\
\text { (total) }\end{array}$ & 149.5 & 35.71 & 0.383 & 0.000 & 0.348 & 0.000 & 0.427 & 0.000 & 0.487 & 0.000 \\
\hline
\end{tabular}

Based on the results of Table 1, there is a significant positive correlation between the dependence on the mobile phone and its components with psychological disorders $(\mathrm{p}<0.01)$. In the second stage, multiple regressions were used to predict psychological disorders based on components of mobile phone dependency that the findings have been reported in Table 2 .

Table 2 Summary of regression analysis to predict psychological disorders based on the components of mobile phone dependency

\begin{tabular}{lccccc}
\hline & \multicolumn{2}{c}{ Non-standard factors } & Standard factors & \multirow{2}{*}{$\mathrm{T}$} & \multirow{2}{*}{ Sig } \\
\cline { 2 - 4 } & $\mathrm{B}$ & $\mathrm{Std}$. Error & Beta & & \\
\hline Endure deprivation & 2.466 & 0.936 & 0.207 & 2.635 & 0.009 \\
Disruption of life & 1.999 & 1.141 & 0.140 & 1.752 & 0.082 \\
Force-insist & 2.401 & 0.782 & 0.258 & 3.069 & 0.003 \\
\hline $\mathrm{R}=0.488 \quad \mathrm{R}^{2}=0.238$ & $\mathrm{~F}=17.186$ & $\mathrm{Sig}=0.000$ & & &
\end{tabular}

Based on the regression model, the determination coefficient $\left(\mathrm{R}^{2}\right)$ is equal to 0.238 which means that the components of mobile dependency explain $23.8 \%$ of the variance of psychological disorders. Also, the findings show that among the components of mobile dependency, the forceinsist with $\beta(0.258)$ and endure deprivation with $\beta(0.207)$ were the most probable predictor of psychological disorders among students $(\mathrm{p}<0.01)$. 
To determine the relationship of mobile phone dependency and academic burnout in the first stage, the Pearson correlation coefficient was used that the findings have been reported in Table 3.

Table 3 Correlation coefficients of dependence on cell phone and academic burnout

\begin{tabular}{lccccccccccc}
\hline \multirow{2}{*}{ Variable } & \multicolumn{4}{c}{$\begin{array}{c}\text { Deprivation } \\
\text { endure }\end{array}$} & \multicolumn{2}{c}{ Disruption of life } & \multicolumn{2}{c}{ Force-insist } & \multicolumn{3}{c}{$\begin{array}{c}\text { Total dependence } \\
\text { on mobile phone }\end{array}$} \\
\cline { 2 - 12 } & $\mathrm{M}$ & $\mathrm{Sid}$ & $\mathrm{r}$ & $\mathrm{P}$ & $\mathrm{r}$ & $\mathrm{P}$ & $\mathrm{r}$ & $\mathrm{P}$ & $\mathrm{r}$ & $\mathrm{P}$ \\
\hline Academic fatigue & 14.63 & 3.55 & 0.221 & 0.004 & 0.291 & 0.000 & 0.798 & 0.000 & 0.594 & 0.000 \\
Academic apathy & 17.07 & 2.37 & 0.103 & 0.183 & 0.788 & 0.000 & 0.295 & 0.000 & 0.455 & 0.000 \\
Academic failure & 17.07 & 2.37 & 0.708 & 0.000 & 0.095 & 0.218 & 0.211 & 0.006 & 0.423 & 0.000 \\
$\begin{array}{l}\text { Academic burnout } \\
\text { (total) }\end{array}$ & 53.26 & 6.29 & 0.449 & 0.000 & 0.500 & 0.000 & 0.647 & 0.000 & 0.677 & 0.000 \\
\hline
\end{tabular}

Table 4 Summary of regression analysis to predict academic fatigue based on the components of cell phone dependency

\begin{tabular}{lcccccc}
\hline & \multicolumn{2}{c}{ Non-standard factors } & \multicolumn{2}{c}{ Standard factors } & \multirow{2}{*}{ T } & \multirow{2}{*}{ Sig } \\
\cline { 2 - 4 } & $\mathrm{B}$ & Std. Error & Beta & & \\
\hline Endure deprivation & 0.304 & 0.137 & 0.145 & 2.219 & 0.028 \\
Disruption of life & 0.522 & 0.167 & 0.207 & 3.126 & 0.002 \\
Force-insist & 0.779 & 0.114 & 0.474 & 6.806 & 0.000 \\
\hline $\mathrm{R}=0.69 \quad \mathrm{R}^{2}=0.476$ & $\mathrm{~F}=49.871 \quad \mathrm{Sig}=0.000$ & & &
\end{tabular}

Based on the results of Table 3, there is a significant positive correlation between the dependence on the cell phoneand its components with academic fatigue $(p<0.01)$. In the second stage, multiple regressions were used to predict academic fatigue based on components of mobile phone dependency that the findings have been reported in Table 4 .

Based on the regression model, the determination coefficient $\left(\mathrm{R}^{2}\right)$ is equal to 0.476 which means that the components of mobile dependency explain $47.6 \%$ of the variance of academic burnout. Also, the findings show that among the components of mobile dependency, the force-insist with $\beta(0.474)$ and disruption of life with $\beta(0.207)$ and endure deprivation with $\beta(0.145)$ were the most probable predictor of academic burnout among students $(\mathrm{p}<0.01)$.

\section{Discussion}

The results showed there is a significant positive relationship between the dependence on mobile phone and psychological disorders and dependence on mobile phone explains $23.8 \%$ of the variance of students' psychological disorders. In explaining these findings it can be said that students who increase the hours of mobile phone use and spend more time for web-browsing, chat, etc. may have feelings such as loneliness, depression because they spend their time on the internet and loneliness and anxiety and guilt due to waste their time and in general with increasing use of mobile phone score of psychiatric indices increases. Roberts et al. found significant relationship between symptoms of addiction to mobile phone and depression [30]. Also the results showed a positive correlation between depression and anxiety and the number of SMS messages sent per day and loss of control and social anxiety [31].

Study of Amidtaher et al showed that there is a significant relationship between anxiety and the use of mobile phone [32]. Excessive Mobile phone use reduces social interactions and creates feelings of loneliness [33]. Based on other studies, the problematic use of mobile phone is positively correlated with aggression, smoking, suicide, low self-esteem at all ages and both genders [12]. According to Kajbaf et al. internet addiction is significantly correlated with depression, hypochondriasis, anxiety, obsession, interpersonal sensitivity, the fear and paranoia, and also the overall symptoms index [26]. In general, health complaints such as fatigue, stress, and anxiety and sleep disorders in people who regularly use mobile phone are more than those who rarely use [29]. Another finding of this study showed that there 
is a significant positive relationship between the dependence on mobile phone and academic burnout and dependence on mobile phones explains 47.6 percent of the variance of students' academic burnout. In explaining these findings, it can be said that students with excessive mobile phone use compared with students who have less mobile use, assign shorter time to study and homework and even while doing homework their concentration is on the mobile phone. The result will be less accuracy on the material which results in feeling more academic burnout. The relationship between dependence on mobile and academic burnout has been proven in previous studies. Findings from other studies show that there is positive significant relationship between dependence on mobile phone and increasing unhealthy relations and reduce motivation and academic achievement [34-36]. The overuse and misuse of mobile phone create major problems in personal, social and academic fields [37].

\section{Conclusion}

In general, the results of this study indicate that having a mobile phone for a long time causes higher mobile phone use in the students and will be a replacement for their meetings with family and friends and therefore the absence of faceto-face communication reduces mental health. The long-term use of mobile phones causes that this group of students devote less time to study lessons and therefore they experience academic burnout. Thus, according to the results of this study it is required to design and implement appropriate interventions to check and reduce dependence on mobile phone at the Faculty of Nursing and Midwifery. It is recommended for teachers in life skills courses to consider individual pathology and social dependence on their mobile phone. It also recommended for manager of school's extra-curricular and cultural program to hold educational workshops in addiction to mobile phones and problems and issues. The limitation of this study is its crosssectional characteristic, while mobile phone dependency and its resulting consequences need more continuous and long term studies to be able to identify the relationship between this disorder with the psychological disorders and academic burnout.

\section{Contribution}

Study design: NN, RNK, ZGh

Data collection and analysis: NN, RNK, ZGh Manuscript preparation: NN, RNK, ZGh

\section{Acknowledgments}

The authors gratefully acknowledge the all participants whom cooperated in this survey. Hereby thank all those who cooperated with us in conducting this study, specially the students participated in this are appreciated

\section{Conflict of Interest}

"The authors declare that they have no competing interests."

\section{Funding}

The author(s) received no financial support for the research, authorship and/or publication of this article.

\section{References}

1- Bellina L, Missoni E. Mobile cell-phones (M-phones) in telemicroscopy: increasing connectivity of isolated laboratories. Diagn Pathol2009; 4(19): 1-4.

2- Takao M, Takahashi S, Kitamura M. Addictive personality and problematic mobile phone use. Cyberpsychol Behav2009; 12(5): 501-07.

3- Kosari M, Javadi Yegane MR, Kheyrkhah T. Mobile application for Iranian users, with an emphasis on using and satisfaction theory. Culture and Communication Studies2006; 2(7): 205-26.

4- De-Sola Gutiérrez J, Rodríguez De Fonseca F, Rubio G. Cell-phone addiction: a review. Front Psychiatry2016; 7: 175 .

6- Billiex J, Vander der Linden M, Rochat L. The role of impulsivity in actual and problematic use of the mobile phone. Appl Cogn Psychol2008; 22(9): 1195-210.

8- Kwon Y, Paek K. The influence of smartphone addiction on depression and communication competence among college students. Indian J Sci Technol2016; 9(41): 1-8.

9- Jenaro C, Flores N, Gomez M, Gonzlez-Gil F, Caballo C. Problematic internet and cell-phone use: psychological, behavioral, and health correlates. Addict Res Theory2007; 15(3): 309-20.

10- Rutland JB, Sheets T, Young T. Development of a scale to measure problem use of short message service: the 
SMS problem use diagnostic questionnaire. Cyberpsychol Behav2007; 10(6): 841-43.

11- Dadsetan P. Mobile phone: another addictions. Journal of developmental Psychology2009; 4(15): 214-16.

12- Takao M, Takahashi S, Kitamura M. Addictive personality \& problematic mobile phone use. Cyberpsychol Behav2009; 12(5): 501-05.

13- Kamibeppu K, Sugiura H. Impact of the mobile phone on junior high school students' friends hips in the Tokyo metropolitan area. Cyberpsychol Behav2005; 8(2): 121-30. 14- Khazaee T, Saadatjoo A, Shabani M, Senobari M, Baziyan M. Prevalence of mobile phone dependency and its relationship with students' self esteem. Knowledge \& Health2014; 8(4): 156-62.

15- Vizeshfar F. Assessment of the internet addiction between larian net users. The Quarterly Journal of Fundamentals of Mental Health2005; 7(25-26): 27-33.

16- Khajehmougahi N, Alasvand M. The studying of predictor personality variables of internet addiction. Jundishapur Scientific Medical Journal2010; 9(4): 360-66. 17- Zarbakhsh Bahri M, Rashedi V, Khademi M. Loneliness and internet addiction in students. Journal of Health Promotion Management2013; 2(1): 32-8.

18- Westerhof GJ, Keyes CL. Mental illness and mental health: the two continua model across the lifespan. J Adult Dev2010; 17(2): 110-19.

19- McLeod JD, Uemura R, Rohrman S. Adolescent mental health, behavior problems, and academic achievement. $J$ Health Soc Behav2012; 53(4): 482-97.

20- Abdulghani HM, AlKanhal AA, Mahmoud ES, Ponnamperuma GG, Alfaris EA. Stress and its effects on medical students: a cross-sectional study at a college of medicine in Saudi Arabia. J Health Popul Nutr2011; 29(5): 516-22.

21- Lin Sh, Huang Y. Life stress and academic burnout. Active Learning in Higher Education2013; 15(1): 77-90.

22- Palacio JE, Caballero CC, González O, Gravini M, Contreras KP. Relationship between burnout and coping strategies with GPA in university students. Univ Psycho2012; 11(2): 535-44.

23- Naami A. Relationship between the quality of students learning experience with burnout MA shahid chamran university. Journal of Psychological Studies2009; 5(3): 117-34.

24- Koo HY. Development of a cell phone addiction scale for korean adolescents. J Korean Acad Nurs2009; 39(6): 818-28.

25-Abdollahian E, Fayyazi Bordbar MR, Rezaee GR, Ghani Kakhaki M. Psychological problems in medical students of Mashhad University of Medical Science. Medical Journal of Mashhad University of Medical Sciences2003; 46(80):
11-8.

26- Bresó E, Salanova M, Schaufeli WB. In search of the third dimension of burnout: efficacy or inefficacy? Applied Psychology: An international Review2007; 56(3): 460-78.

27- Hosseinpour E, Asgari A, Ayati M. The relationship between internet and cell-phone addictions and academic burnout in University Students. Information and Communication Technology in Educational Sciences2016; 6(4): 59-73.

28- Roberts JA, Yaya LH, Manolis C. The invisible addiction: Cell-phone activities and addiction among male and female college students. J Behav Addict2014; 3(4): 254-65.

29- Billieux J, linden M, Acremont M, Ceschi G, Zermatten A. Does impulsivity relate to perceived dependence on and actual use of the mobile phone? Applied Cognitive Psychology2007; 21(4): 527-37.

30- Amidtaher M, Saadatmand S, Moghadam Z, Fathi G, Afshar R. The relationship between mobile Cellphone dependency, mental health and academic achievement. Am J Educ Res2016; 4(5): 408-11.

31- Repacholi MH. Health risks from the use of mobile phones. Toxicol Lett2001; 120(1-3): 323-31.

32- Kajbaf MB, Kooraki M, Saffarian Z. Comparison of psychological disorders in addicted and non adidicted students to the internet in University of Isfahan. Journal of Hormozgan University of Medical Sciences2014; 18(2): 169-76.

33- Panahi Y, Aslani T, Faraji R, Betvaz H. Dependence on mobile phone and psychological-social damages in students, the study of effects of SMS and bluetooth. The First Congress of Cyber Space and Social Problem, 2013. 34- Leep A, Barkley JE, Karpinski AC. The relationship between Cell phone use and academic performance in a sample of U.S. College Students. SAGE Open2015; 5(1): $1-9$.

35- Jacobsen WC, Forste R. The wired generation: academic and social outcomes of electronic media use among university students. Cyberpsychol Behav Soc Netw2011; 14(5): 275-80

36-Rostaminejhad MA, Vahdani Asadi MR, Izi M, Rouhani Z. Management of mobile phone damages at school: Hesitation on its positive and negative functions. The Studies of Management on Police Training2014; 1(25): 61-76.

37- Rostaminejhad MA, Vahdani Asadi MR, Izi M, Rouhani Z. Management of mobile phone damages at school: Hesitation on its positive and negative functions. The Studies of Management on Police Training2014; 1(25): 61-76.

\footnotetext{
Copyright(C) 2016 ASP Ins. This open-access article is published under the terms of the Creative Commons Attribution-NonCommercial 4.0 International License which permits Share (copy and redistribute the material in any medium or format) and Adapt (remix, transform, and build upon the material) under the Attribution-NonCommercial terms.
} 